\title{
Dissociating mere exposure and repetition priming as a function of word type
}

\author{
LAURIE T. BUTLER and DIANNE C. BERRY \\ University of Reading, Reading, England \\ and \\ SHAUN HELMAN \\ University of Wales Institute, Cardiff, Wales
}

\begin{abstract}
The mere exposure effect is defined as enhanced attitude toward a stimulus that has been repeatedly exposed. Repetition priming is defined as facilitated processing of a previously exposed stimulus. We conducted a direct comparison between the two phenomena to test the assumption that the mere exposure effect represents an example of repetition priming. In two experiments, having studied a set of words or nonwords, participants were given a repetition priming task (perceptual identification) or one of two mere exposure (affective liking or preference judgment) tasks. Repetition priming was obtained for both words and nonwords, but only nonwords produced a mere exposure effect. This demonstrates a key boundary for observing the mere exposure effect, one not readily accommodated by a perceptual representation systems (Tulving \& Schacter, 1990) account, which assumes that both phenomena should show some sensitivity to nonwords and words.
\end{abstract}

Zajonc (1968) posited that "the mere repeated exposure of the individual to a stimulus is a sufficient condition for the enhancement of his attitude toward it" (p. 1). Over the last 35 years, there have been many demonstrations of this simple phenomenon, termed the mere exposure effect (see Bornstein, 1989, for a review), using a broad range of procedures and materials. For example, recent studies have employed stimuli as diverse as advertisements (Janiszewski \& Meyvis, 2001), Turkish words (Marie et al., 2001), photographs of people (Zárate, Sanders, \& Garza, 2000), Chinese ideographs (Monahan, Murphy, \& Zajonc, 2000), and polygons (Seamon, McKenna, \& Binder, 1998). Despite the interest that the phenomenon has generated, however, a widely accepted theoretical interpretation remains elusive. Of those that have been proposed over the years (e.g., Berlyne, 1974; Harrison, 1977), the primacy of affect (Zajonc, 1980, 2000) and the attribution of fluency (Bornstein \& D'Agostino, 1994; Seamon, Brody, \& Kauff, 1983) theories have been most influential.

Increasingly, though, the mere exposure effect has been described as an example of implicit memory (e.g., Bornstein \& D'Agostino, 1992; Jacoby \& Kelley, 1987; Schacter, 1987; Squire, 1992). Implicit memory is defined as the nonintentional, nonconscious retrieval of previously acquired information and is demonstrated on tasks that do not require conscious, intentional recollec-

This research was supported by an Economic and Social Research Council (ESRC) grant (R00233329) awarded to L.T.B. and D.C.B. We thank Paula Brown for her assistance in data collection. Correspondence should be addressed to L. T. Butler, School of Psychology, University of Reading, Earley Gate, Whiteknights, Reading RG6 6AL, England (e-mail: 1.t.butler@reading.ac.uk). tion of past experiences (Graf \& Schacter, 1985). By definition, the fact that the mere exposure effect can be obtained without reference to the initial learning episode means that it would qualify as an example of implicit memory in its broadest sense (as might implicit learning, for example). However, tacit in this is the assumption that the mere exposure effect belongs to a particular implicit memory subgroup - namely, repetition priming (as measured by tasks such as perceptual identification and word fragment completion; see Butler \& Berry, 2001b; Fleischman \& Gabrieli, 1998; Seamon et al., 1995). Repetition priming occurs when prior exposure to a stimulus biases or facilitates the processing of that stimulus on subsequent exposures. Although this link between repetition priming and mere exposure is intuitively appealing, not least because of the opportunity it accords to accommodate the latter within an established theoretical framework (e.g., Roediger, Weldon, \& Challis, 1989; Tulving \& Schacter, 1990), there have been few attempts to explore it directly.

Seamon and colleagues (1995; Seamon et al., 1997) have made some progress in this respect, reporting a number of parallels between mere exposure and repetition priming. For example, Seamon et al. (1997) found that study-to-test changes in retinal size and left-right orientation produced the same pattern of results using a mere exposure task, as had been previously reported with an object decision task (Cooper, Schacter, Ballesteros, \& Moore, 1992). However, although compelling, not all evidence shows such a convergence. In a recent review, Butler and Berry (in press) highlighted what appear to be a number of important differences between the two phenomena. For example, whereas increasing the number of times a stimulus is exposed at study appears to have lit- 
tle effect on performance on perceptual repetition priming tasks (e.g., Jacoby \& Dallas, 1981), the same variable often increases the size of the mere exposure effect (e.g., Bornstein \& D'Agostino, 1992). One caveat with such comparisons is that they have tended to reflect the output of independent studies that have examined either one or the other of the phenomena, but not both together. This makes interpretation difficult, given that these studies typically differ in other ways as well, such as in terms of procedural details and materials employed. Therefore, the aim of the present article is to provide a direct comparison of the two phenomena. In so doing, we report new experimental data that provide further evidence that the relation between mere exposure and repetition priming should be accorded closer scrutiny.

In accounting for their data, Seamon et al. (1997) applied a multiple memory systems framework (e.g., Schacter, 1994; Tulving \& Schacter, 1990) to the mere exposure effect. Specifically, they suggested that affective preference judgments are mediated by a structural description system, a subsystem of the perceptual representation system (PRS) described by Tulving and Schacter. The structural description system, which encodes the structural relations among parts of an object, has previously been implicated in nonverbal repetition priming tasks such as the object decision task (Schacter, 1994; Schacter, Cooper, \& Delaney, 1990). By this view, then, both mere exposure and repetition priming for objects reflect the operation of a common representation system. Although not discussed by Seamon et al. (1995), presumably a similar relation might exist in the case of verbal stimuli. As part of the architecture of the PRS, Tulving and Schacter proposed that a visual word form system subserves repetition priming for verbal materials. This system is characterized as encoding information about the visual and orthographic form of words and, in creating novel representations, is thought to support priming for both nonwords and familiar words (see Schacter, 1994). Therefore, following Seamon et al.'s (1997) lead, a visual word form system might also mediate mere exposure effects for verbal materials. If this is correct, then a seemingly straightforward prediction would be that mere exposure and repetition priming should display some sensitivity to both words and nonwords.

The existing literature on nonwords indicates that such materials do produce reliable repetition priming (e.g., Bowers, 1996; Dorfman, 1998) and mere exposure effects (Dorfman, 1994; Marie et al., 2001). Furthermore, the repetition priming literature contains numerous examples of priming effects for words (see Roediger \& McDermott, 1993, for a review). However, the picture with regard to mere exposure and words is less clear. At first glance, the evidence would seem to complement that for repetition priming, with Bornstein (1989), in an influential and widely cited meta-analytical review, reporting that meaningful words produce some of the largest effects of all. A closer inspection of individual studies, though, reveals that nearly all the reported mere exposure effects for real words actually reflect correlational data between word frequency counts and liking ratings rather than experimental manipulations of exposure per se (see, e.g., Harrison, 1969; Sluckin, Colman, \& Hargreaves, 1980). Indeed both of the experimental studies of which we are aware (Amster \& Glasman, 1966; Grush, 1976) failed to obtain a significant mere exposure effect for positive real words.

Therefore, in contrast to what might be predicted on the basis of access to a visual word form system (Tulving \& Schacter, 1990), the available evidence suggests that mere exposure effects are not observed for real words. This is all the more striking given that much of the repetition priming literature is based upon observations using such stimuli. However, this apparent difference must be treated cautiously given that the evidence is drawn from largely independent literatures employing different methodologies. In this article, for the first time, we directly compare the two phenomena using a set of real words and also a carefully matched set of nonwords. If mere exposure and repetition priming do reflect the operation of a common underlying representation system (visual word form system), then both phenomena should be obtained for words and nonwords.

In Experiment 1, we compare performance on common measures of repetition priming and mere exposurenamely, perceptual identification and affective liking. In addition to being used extensively in their respective literatures, the tasks are well matched in that stimuli are presented in the same format at test (i.e., complete single items), albeit only briefly in the case of perceptual identification. In Experiment 2, by way of extension, we introduce a second commonly used measure of mere exposure (preference judgment). Additionally, we include a measure of explicit recognition to address an issue raised in Experiment 1.

\section{EXPERIMENT 1}

\section{Method}

Participants. Ninety-four undergraduate students from the University of Reading participated in the experiment, for which they received either course credit or a small cash payment. Forty-four participants were randomly assigned to a repetition priming condition ( 22 each for words and nonwords) and 50 participants to a mere exposure condition ( 25 each for words and nonwords).

Design. The experiment employed a 2 (test type: affective liking vs. perceptual identification) $\times 2$ (stimulus type: words vs. nonwords) $\times 2$ (exposure: studied vs. nonstudied) mixed factor design, with repeated measures on the latter factor.

Materials. A key requirement for the stimuli was that they could be used in conjunction not only with affective liking and perceptual identification tasks, but also with a preference judgment task (see Experiment 2). To meet this, 240 word pairs and 120 nonword pairs were initially generated. Words were selected from a pool formed by searching the MRC psycholinguistic database for two-syllable words with a Thorndike-Lorge frequency count of less than or equal to 25 . The frequencies selected fell between the ranges defined by Thorndike and Lorge (1944) as low (1-9) and medium (19-49). Pronounceable nonwords were created by combining two morphemes (prefix, suffix, or base morphemes) from a corpus devised by Ljung (1974). Words and nonwords within a pair were matched for number of letters, and had at least the first two letters 
in common (e.g., Dorfman, 1994). Each stimulus was then rated for liking (stimuli presented individually) and for preference (stimuli presented in pairs). Due to the large volume of stimuli, each participant in the norming study (total $n=180$ ) rated a subset of the available stimuli. Overall, this meant that each stimulus was rated for liking and separately for preference (as part of a pair) by 20 participants. Liking ratings were made on the following 6-point scale: (1) really dislike, (2) dislike, (3) sort of dislike, (4) sort of like, (5) like, (6) really like. For preference ratings, participants simply circled the stimulus that they preferred within each pair.

From the resulting norming data, 32 word pairs and 32 nonword pairs (see Appendix) were selected. For words and nonwords separately, four lists each containing 16 items were created. These were arranged so that Lists $\mathrm{A} 1$ and $\mathrm{A} 2$ and Lists $\mathrm{B} 1$ and $\mathrm{B} 2$ were paired. The lists were closely matched; those stimuli within each pair (e.g., List A1 and List A2 items) were matched for liking and preference. Furthermore, mean ratings were matched across lists (e.g., between Lists A1 and B1). Finally, the lists were constructed so that both words and nonwords were matched overall for mean liking (3.10 and 2.99 , respectively).

At study, participants were presented with one of the eight possible lists (Lists A1, A2, B1, or B2 for words or nonwords). The lists were rotated and counterbalanced across participants. At test, for affective liking, perceptual identification and recognition (Experiment 2) tasks, participants received the studied list (e.g., List A1) in conjunction with the corresponding nonstudied list (e.g., List B1). For preference judgment only (Experiment 2), participants viewed stimulus pairs comprising targets from the studied list (e.g., List A1) and distractors from the paired nonstudied list (e.g., List A2). Pairs from the remaining lists (e.g., Lists B1 and B2) served as additional distractors in this case. The position of targets and distractors (i.e., left and right) was randomized and fully counterbalanced for each participant. Overall, arranging the stimuli in this way meant that, regardless of test condition, all participants received 16 stimuli at study and 32 at test (either single items or pairs). Presentation orders were fully randomized at both study and test for each participant.

A filler task was also created for the purposes of the experiment. The task was a short questionnaire that contained a series of 30 simple mathematical problems (e.g., $4 \times 16$ ). The questionnaire was designed to take no more than $2 \mathrm{~min}$ and, as is common in implicit memory research, was administered between study and test phases.

Procedure. All participants were initially informed that they would be taking part in a study to establish the ease with which people read words (or nonwords). Having been given this cover task, participants were instructed that a series of words (or nonwords) would appear centrally on the computer screen that they should read silently as accurately (but also as quickly) as possible. Participants then saw 16 study items (either word or nonword Lists A1, A2, B1, or B2), presented one at a time for 1,000 msec each. All items were presented in bold Arial size 26 font and were preceded by 4 practice stimuli. Each trial was initiated by means of the space bar, and there was a 1,500-msec delay between trials.

At the end of the study phase, participants were given 2 min to complete the mathematics filler task. Subsequently, they were given instructions for either mere exposure (affective liking) or repetition priming (perceptual identification) tasks. Participants assigned to the mere exposure condition were told that they would be providing normative data on word (nonword) likeability. They were further informed that stimuli would appear one at a time on the computer screen, and that they should indicate, on the 6-point scale provided, how much they liked each stimulus. Participants initially saw 16 practice items, followed by the 32 test words (nonwords). Each item was displayed for $1,000 \mathrm{msec}$, after which it was replaced by a blank screen. Following a keypress (1-6), there was a $1,000 \mathrm{msec}$ delay before the onset of the next item.

Participants assigned to the perceptual identification condition were told they were providing data on word (nonword) identification speed. Participants were further informed that they should simply try to identify stimuli that were flashed briefly upon the screen. Participants then initially attempted to identify aloud 16 practice items displayed in decreasing steps of $100,80,60$, or $40 \mathrm{msec}$ (nonwords) or $80,60,40$, or $20 \mathrm{msec}$ (words), with 4 items presented at each duration. Each item was immediately followed by a mask that consisted of a row of ampersands ( $\& \& \& \& \& \& \& \& \&)$. Responses were recorded by means of a tape recorder and voice key, with participants being told to say "pass" only if they had no idea as to the identity of a particular stimulus. Performance on these practice items was used to determine an exposure duration for test items for each participant. This was taken as the point at which participants identified roughly $50 \%$ of stimuli. As for affective liking, 32 test words (nonwords) were then presented with a 1,000-msec delay before the next item following a response.

\section{Results}

Affective liking. The mean liking ratings for words and nonwords are displayed in Figure 1. Comparison of the ratings given to studied and nonstudied items indicates that only nonwords produced a mere exposure effect. This was confirmed by a 2 (stimulus type: words vs. nonwords) $\times 2$ (exposure: studied vs. nonstudied) mixed analysis of variance (ANOVA). There was a main effect of exposure $\left[F(1,48)=5.77, M S_{\mathrm{e}}=0.10, p<.05\right]$ but not of stimulus type $\left[F(1,48)=1.06, M S_{\mathrm{e}}=0.23\right.$, $p>.05]$, but this finding was qualified by a significant

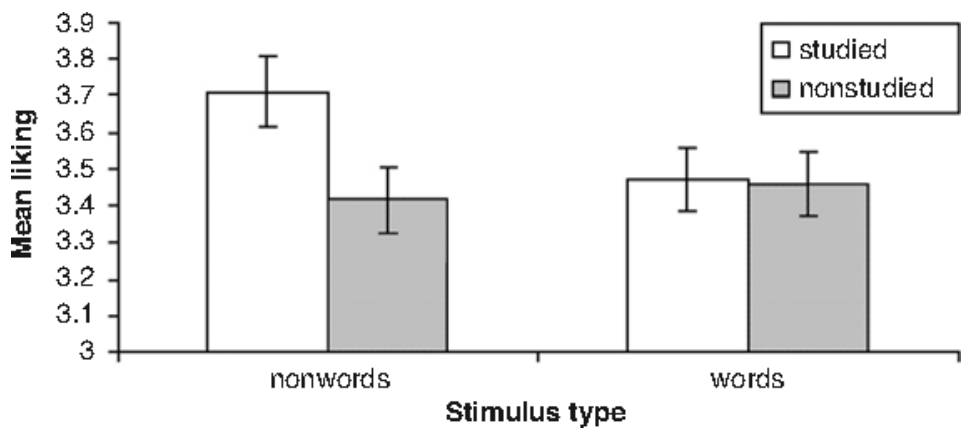

Figure 1. Mere exposure (affective liking) for words and nonwords. Error bars represent $1 S E$ above and below the mean. 
interaction $\left[F(1,48)=4.85, M S_{\mathrm{e}}=0.10, p<.05\right] . t$ tests showed that the effect of exposure (studied vs. nonstudied) was significant for nonwords $[t(24)=3.16, p<.005]$, but not for words $[t(24)=0.15, p>.05]$.

Perceptual identification. Figure 2 displays the data for the perceptual identification participants. Words were associated with a somewhat higher baseline than nonwords, which reflects the variability involved in setting individual thresholds for participants. However, the important comparison is between the mean proportion of studied and nonstudied items correctly identified. As can be seen, both words and nonwords produced equal, and large, amounts of priming. An ANOVA confirmed this, showing significant main effects of exposure $[F(1,42)=$ $\left.28.80, M S_{\mathrm{e}}=0.02, p<.0001\right]$ and of stimulus type $\left[F(1,42)=17.43, M S_{\mathrm{e}}=0.05, p<.0001\right]$, which indicated that overall a greater proportion of words than nonwords were identified. Crucially, though, the interaction was not significant $[F(1,42)<1]$, indicating comparable amounts of significant priming for both words $[t(21)=$ $4.86, p<.0001]$ and nonwords $[t(21)=3.22, p<.001]$.

\section{Discussion}

Repetition priming was observed for both stimulus types, whereas nonwords but not words produced a mere exposure effect. Although consistent with earlier observations (e.g., Amster \& Glasman, 1966; Grush, 1976), the absence of a mere exposure effect for words is in direct contrast to the numerous reports of repetition priming effects for words (see Roediger \& McDermott, 1993). Furthermore, the finding seems difficult to reconcile with the proposal of common access to a visual word form system for the two phenomena.

Given the importance of the null finding, an analysis was conducted to determine the power of the present experiment to detect a mere exposure effect for words. On the basis of the mere exposure effect observed for nonwords, a medium to large (see Cohen, 1988) effect size of .69 was derived. From this, it was calculated that with $n=25$ and $\alpha=.05$ (one-tailed), the power to detect a mere exposure effect for words, similar in magnitude to that obtained for nonwords, was substantial (.78). As further support for the reliability of the finding, it should be noted that recent work carried out in our laboratory, using a different set of materials, also failed to demonstrate a mere exposure effect for words. In brief, in one study, participants rated a series of studied and nonstudied common nouns (e.g., goat, chair) for liking using a 9 -point scale. The difference between studied (5.25) and nonstudied (5.20) ratings was not significant $[t(15)=$ $0.33, p=.74]$. This pattern was replicated in a second study, this time using a 6-point scale (3.56 vs. 3.51$)$ $[t(16)=0.64, p=.53]$.

Notwithstanding this consistent pattern, a second experiment was conducted in the present study to extend the finding to a different measure of mere exposure. Showing that the null effect for words generalizes across measures would provide an even more compelling case because it would dispel any suggestion that the finding was a function of the idiosyncrasies of the affective liking task. A second aim of Experiment 2 was to clarify the results of Experiment 1 by addressing a possible explanation for the absence of a mere exposure effect for words. Specifically, we wondered whether the words that we used were simply more recognizable than the nonwords. According to one popular mere exposure account (Bornstein \& D'Agostino, 1992), participants may be less likely to attribute the fluency that results from exposure to a stimulus to liking if they realize that they have seen that stimulus before. Therefore, if our words were more easily recognized than our nonwords, it would be unsurprising that they generated smaller mere exposure effects. For this reason, Experiment 2 incorporated an explicit recognition condition. To provide an appropriate comparison to the affective liking task used in Experiment 1 , a yes-no recognition task was employed.

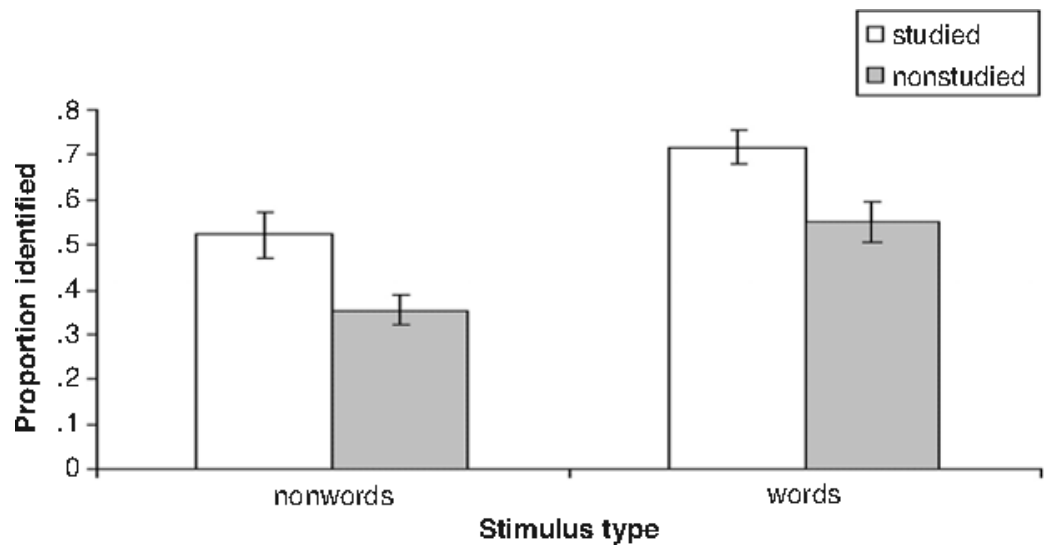

Figure 2. Repetition priming (perceptual identification) for words and nonwords. Error bars represent $1 S E$ above and below the mean. 


\section{EXPERIMENT 2}

\section{Method}

Participants. Seventy-two University of Reading undergraduates took part in the experiment in return for course credit or a small cash payment. Forty participants were randomly assigned to the mere exposure condition (20 each for words and nonwords). On the basis of power analyses performed for Experiment1, it was calculated that this number of participants would be sufficient to demonstrate even a small to medium size effect. A further 32 participants were assigned to the recognition condition (16 each for words and nonwords). None had participated in Experiment 1.

Design. The experiment employed a 2 (test type: preference judgment vs. recognition) $\times 2$ (stimulus type: words vs. nonwords) $\times$ 2 (exposure: studied vs. nonstudied) mixed factor design, with repeated measures on the latter factor.

Procedure. The study and filler task phases were the same as for Experiment 1. At test, participants assigned to the mere exposure (preference judgment) condition were told that they were providing normative data on word (nonword) preferences. They were further informed that pairs of stimuli would appear on screen, one pair at a time, and that they should indicate by means of a keypress ("Z" for left and " $M$ " for right) which item in each pair they preferred. Participants initially saw 16 pairs of practice items, followed by 32 test pairs. Each pair was displayed for 1,000 msec before being replaced by a blank screen. Following a keypress, there was a 1,000 msec delay before the onset of the next pair.

For the recognition condition, participants were told that they would see a series of words (nonwords), some of which they had seen before. They were further informed that they should use their memories to help decide whether they recognized a particular word (nonword) as having being studied. Following 16 filler items, which participants treated as practice items, 32 test items were displayed one at a time. Words (nonwords) were each displayed for $1,000 \mathrm{msec}$ followed by a blank screen, which remained blank until participants had made a recognition decision ("Z" for yes or "M" for no). There was then a 1,000-msec delay before the onset of the next item.

\section{Results}

Preference judgment. The proportion of studied items selected over nonstudied ones was much greater for nonwords $(0.61, S D=0.14)$ than for words $(0.52, S D=0.13)$. A between-participants $t$ test showed that the selection rates for the two stimulus types were significantly different from each other $[t(38)=2.25, p<.05]$. Furthermore, single-sample $t$ tests revealed that preference for studied stimuli was significantly above that which would be expected by chance (i.e., .5) in the case of nonwords $[t(19)=3.67, p<.01]$, but not words $[t(19)<1]$.

Recognition. Recognition performance is displayed in Figure 3. As can be seen, the uncorrected performance was slightly higher for nonwords than for words. However, when we take into account false alarms, performance (hits - false alarms) was identical for words $(0.57, S D=$ $0.20)$ and nonwords $(0.57, S D=0.21)$. This was confirmed by a between-participants $t$ test $[t(30)<1]$.

\section{Discussion}

In Experiment 2, using a preference judgment task, mere exposure was again observed for nonwords but not for words. Thus, we have provided a clear replication of the pattern in Experiment 1. Additionally, we found that both stimulus types were equally recognizable. Interestingly, this pattern for recognition was very similar to one recently reported by Mulligan (2002, Experiment 1) for words and pronounceable nonwords that were initially read. Therefore, our data suggest that the lack of a mere exposure effect for words was not due to participants being more likely to recognize them as being studied.

\section{GENERAL DISCUSSION}

Using two different measures, we have shown that mere exposure effects are not obtained using real words, under laboratory conditions at least, even though robust effects are produced for nonwords under exactly the same conditions. In contrast, repetition priming shows no such differential sensitivity, with equal amounts of priming being observed for both words and nonwords. Although dissociations should be interpreted carefully, we believe that this one is particularly noteworthy be-

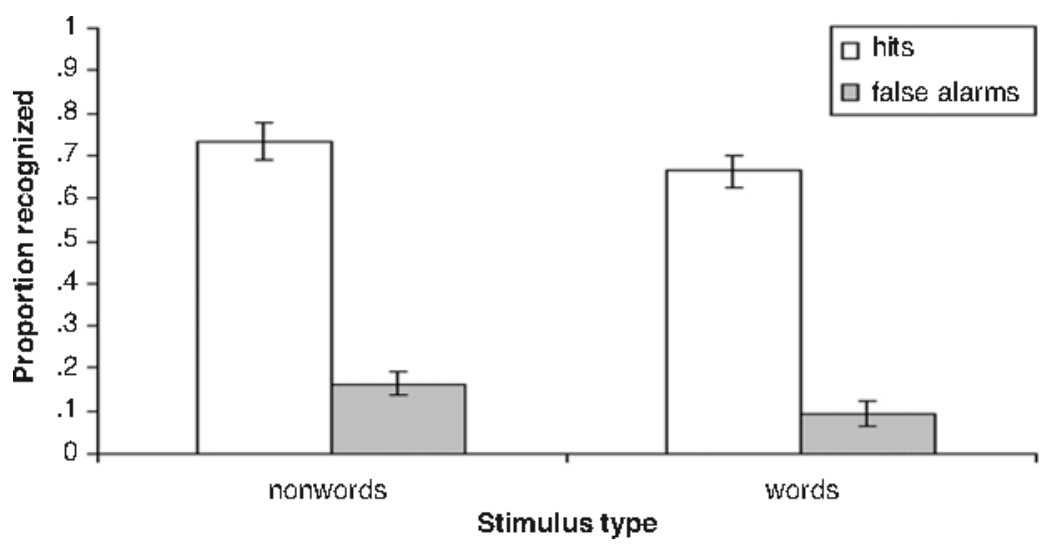

Figure 3. Yes-no recognition for words and nonwords. Error bars represent $1 S E$ above and below the mean. 
cause of the ubiquitous and fundamental nature of priming effects for real words in studies of repetition priming (see Roediger \& McDermott, 1993).

In the next section, we explore potential explanations for the absence of a mere exposure effect for words. First, though, a comment is required regarding the issue of explicit contamination (e.g., Butler \& Berry, 2001a; Richardson-Klavehn, Gardiner, \& Java, 1996). As is standard in studies of implicit memory, we incorporated a number of methodological safeguards (e.g., filler task, cover task, etc.) in an attempt to minimize the likelihood that performance on our mere exposure and repetition priming tasks would be compromised by the use of explicit memorial strategies. Consistent with this, during debriefing none of the participants in these test conditions reported intentionally trying to retrieve study items. However, even assuming some degree of explicit contamination, it is not clear how this could satisfactorily explain the present pattern of results. Presumably, the likelihood of explicit contamination would need to vary jointly as a function of the type of stimuli and the particular test task employed. A priori, it is not obvious why this should be the case.

Earlier in this article, we proposed that if repetition priming and mere exposure reflected the operation of a visual word form system (e.g., Tulving \& Schacter, 1990), then both phenomena should display some sensitivity to words and nonwords. That a mere exposure effect was not obtained for words is seemingly problematic for this view. One solution might be provided by Bowers $(1996,2000)$ who argued that two different word form systems tend to mediate repetition priming for words and nonwordsnamely, an abstract orthographic system for words and a perceptually specific system for nonwords. On this basis, one might argue that mere exposure is mediated largely by the latter system.

We believe, however, that an alternative explanation based on the way in which processing fluency is interpreted might also accommodate the present data. The account draws upon recent work by Whittlesea and Williams $(1998,2000)$ concerning the source of feelings of familiarity in recognition decisions. Their basic proposal is that such feelings are based on the perception of the discrepancy between expected and actual fluency. To illustrate, using an example from Whittlesea and Williams (1998), seeing a previously encountered (and therefore fluently processed) shop assistant in the same store may not generate any subjective reaction because this increased efficiency of processing is unsurprising. However, seeing that same assistant on the bus may generate a powerful feeling of familiarity because you have an expectation that all passengers should be strangers and hence not fluently processed.

We believe that these same principles could help to explain why mere exposure effects are obtained for nonwords but not for words. Essentially, we propose that, in the case of real words, participants generally expect to be able to process such stimuli efficiently. As such, the increased fluency associated with recently studied items is unsurprising and is not interpreted in terms of liking or preference. Conversely, participants do not normally expect to process nonwords efficiently, so when they do, as happens following an earlier exposure, they interpret this unexpected fluency in terms of liking. Work is currently under way in our laboratory to explore this idea further, and one intriguing possibility is that our mere exposure effect for pronounceable nonwords may disappear if participants are led to believe that they are in fact rating unfamiliar but real words.

By this view, a single exposure is sufficient to support repetition priming but not mere exposure because of the way in which the processing fluency is interpreted in the latter phenomenon. Since fluency does not need to be interpreted in repetition priming tasks, but rather is experienced directly as priming, effects for both words and nonwords are observed. However, it should be noted that there are other possible explanations that deserve brief comment here. One possibility is that preferences for words were already fully established before the start of the experiment and therefore unlikely to have been changed by a single experimental exposure. Zajonc (1968) alluded to this sort of idea: "Adding one more occasion (or even 10 more occasions) to see and say a perfectly wellknown English word to all the times this word had been seen and uttered by the individual in the past - a figure often in the thousands - really shouldn't have much effect on the meaning he attributes to it" (p. 15). However, although this may be the case for very high frequency words, it is questionable whether this can generalize to the lower frequency words ( $\mathrm{T}-\mathrm{L}$ count $<25$ ) employed here. Such an explanation looks even less compelling given that in other work (Coates, Butler, \& Berry, in press; see also Chung \& Szymanski, 1997), we and others have produced reliable mere exposure effects using real brand names (e.g., Bold vs. Persil laundry soap). It seems likely that common brand names such as these will have been seen very often. If the frequency explanation were correct, then presumably we would not expect to observe a mere exposure effect for real brand names either.

Finally, a related possibility is that participants were rating and choosing real words on the basis of preexperimental favorites. For example, were participants choosing ensconce over encroach on the basis of some preestablished preference? Although possibly the case for the occasional word, a close look at the stimuli employed makes this seem less plausible as a general strategy. Remember that our words were very closely matched for liking and preference, and were initially selected on the basis that they were not strongly liked or preferred.

Although further work will be required to discriminate between the various explanations offered here, the current dissociation nonetheless demonstrates a key boundary for observing mere exposure effects, and one that is not readily accommodated by a standard repetition prim- 
ing account (e.g., Tulving \& Schacter, 1990). Elsewhere, we have noted that mere exposure and repetition priming may also diverge in other theoretically important ways (see Butler \& Berry, in press, for a review). For example, whereas increasing the number of study exposures seems to have relatively little effect on repetition priming (e.g., Jacoby \& Dallas, 1981), there is evidence that the same manipulation seems to increase the size of the mere exposure effect (e.g., Bornstein \& D'Agostino, 1992), at least initially. Furthermore, whereas repetition priming has been associated with reductions of blood flow in occipital regions (Schacter, Alpert, Savage, Rauch, \& Alpert, 1996; Squire, 1992), mere exposure has been associated with increases of blood flow in regions including the right lateral prefrontal cortex (Elliott \& Dolan, 1998). In interpreting these various findings, though, it is important to remember that these apparent differences require direct confirmation using the sort of design employed in this article. Additionally, any theorizing must be tempered by the fact that Seamon et al. (1995; Seamon et al., 1997) have reported a number of clear parallels between mere exposure and repetition priming.

At the moment, our best view is that mere exposure represents a special affective form of repetition priming, accessing at least a partially similar underlying representation to that supporting repetition priming. This is broadly consistent with the notion, outlined earlier, of mere exposure sharing a perceptually specific word form system with repetition priming but not an abstract orthographic system, or with one where the two reflect the operation of a common system (e.g., visual word form system) but where the output is interpreted differently. Clearly, a primary goal for future research will be to distinguish between these alternatives. The present study has shown that real words, so often a feature in repetition priming studies (see Roediger \& McDermott, 1993, for a review), do not seem to support mere exposure effects.

\section{REFERENCES}

Amster, H., \& Glasman, L. D. (1966). Verbal repetition and connotative change. Journal of Experimental Psychology, 71, 389-395.

BerLyne, D. E. (1974). Novelty, complexity and interestingness. In D. E. Berlyne (Ed.), Studies in the new experimental aesthetics: Steps toward an objective psychology of aesthetic appreciation (pp. 175181). Washington, DC: Hemisphere.

Bornstein, R. F. (1989). Exposure and affect: Overview and metaanalysis of research, 1968-1987. Psychological Bulletin, 106, 265-289.

Bornstein, R. F., \& D'Agostino, P. R. (1992). Stimulus recognition and the mere exposure effect. Journal of Personality \& Social Psychology, 63, 545-552.

Bornstein, R. F., \& D'A Gostino, P. R. (1994). The attribution and discounting of perceptual fluency: Preliminary tests of a perceptual fluency/ attributional model of the mere exposure effect. Social Cognition, 12, 103-128.

Bowers, J. S. (1996). Different perceptual codes support priming for words and pseudowords: Was Morton right all along? Journal of Experimental Psychology: Learning, Memory, \& Cognition, 22, 13361353.

BowERs, J. S. (2000). In defense of abstractionist theories of repetition priming and word identification. Psychonomic Bulletin \& Review, ${ }_{2}$ 83-99.
ButLer, L. T., \& BerRy, D. C. (2001a). Implicit memory: Intention and awareness revisited. Trends in Cognitive Sciences, 5, 192-197.

Butler, L. T., \& BerRY, D. C. (2001b). Transfer effects in implicit memory and consumer choice. Applied Cognitive Psychology, 15, 587-601.

BUTLER, L. T., \& BERRY, D. C. (in press). Understanding the relationship between repetition priming and mere exposure. British Journal of Psychology.

Chung, S. W., \& Szymanski, K. (1997). Effects of brand name exposure on brand choices: An implicit memory perspective. Advances in Consumer Research, 24, 288-294.

CoAtes, S., Butler, L. T., \& Berry, D. C. (in press). Implicit memory: A prime example for brand consideration and choice. Applied Cognitive Psychology.

COHEN, J. (1988). Statistical power analysis for the behavioral sciences (2nd ed.). Hillsdale, NJ: Erlbaum.

Cooper, L. A., Schacter, D. L., Ballesteros, D. L., \& Moore, C. (1992). Priming and recognition of transformed three-dimensional objects: Effects of size and reflection. Journal of Experimental Psychology: Learning, Memory, \& Cognition, 18, 43-57.

DoRFMAN, J. (1994). Sublexical components in implicit memory for novel words. Journal of Experimental Psychology: Learning, Memory, \& Cognition, 20, 1108-1125.

DorfMAN, J. (1998). Further evidence for sublexical components in implicit memory for novel words. Memory \& Cognition, 26, 1157-1172.

Elliott, R., \& Dolan, R. J. (1998). Neural response during preference and memory judgments for subliminally presented stimuli: A functional neuroimaging study. Journal of Neuroscience, 18, 4697-4704.

Fleischman, D. A., \& Gabrieli, J. D. E. (1998). Repetition priming in normal aging and Alzheimer's disease: A review of findings and theories. Psychology \& Aging, 13, 88-119.

Graf, P., \& Schacter, D. L. (1985). Implicit and explicit memory for new associations in normal and amnesic subjects. Journal of Experimental Psychology: Learning, Memory, \& Cognition, 11, 501-518.

GRUSH, J. E. (1976). Attitude formation and mere exposure phenomena: A nonartifactual explanation of empirical findings. Journal of Personality \& Social Psychology, 33, 281-290.

HARRISON, A. A. (1969). Exposure and popularity. Journal of Personality, 37, 359-377.

HARRISON, A. A. (1977). Mere exposure. In L. Berkowitz (Ed.), Advances in experimental psychology (Vol. 10, pp. 39-83). New York: Academic Press.

JACOBY, L. L., \& Dallas, M. (1981). On the relationship between autobiographical memory and perceptual learning. Journal of Experimental Psychology: General, 110, 303-340.

JACOBY, L. L., \& KeLley, C. M. (1987). Unconscious influences of memory for a prior event. Personality \& Social Psychology Bulletin, 13, 314-336.

JANISZEWSKI, C., \& MeYvis, T. (2001). Effects of brand logo complexity, repetition, and spacing on processing fluency and judgment. Journal of Consumer Research, 28, 18-32.

LJUNG, M. (1974). A frequency dictionary of English morphemes. Stockholm: AWE/Gerbers.

Marie, A., Gabrieli, J. D. E., Vaidya, C., Brown, B., Pratto, F., ZAJONC, R. B., \& SHAW, R. J. (2001). The mere exposure effect in patients with schizophrenia. Schizophrenia Bulletin, 27, 297-303.

Monahan, J. L., Murphy, S. T., \& ZaJonc, R. B. (2000). Subliminal mere exposure: Specific, general, and diffuse effects. Psychological Science, 11, 462-466.

Mulligan, $\bar{N}$. W. (2002). The generation effect: Dissociating enhanced item memory and disrupted order memory. Memory \& Cognition, $\underline{\mathbf{3 0}}$, 850-861.

Richardson-Klavehn, A., Gardiner, J. M., \& JaVa, R. I. (1996). Memory: Task dissociations, process dissociations and dissociations of consciousness. In G. Underwood (Ed.), Implicit cognition (pp. 85158). Oxford: Oxford: University Press.

RoEDIGER, H. L. III, \& MCDERMOTT, K. B. (1993). Implicit memory in normal human subjects. In F. Boller \& J. Grafman (Eds.), Handbook of neuropsychology (Vol. 8, pp. 63-131). Amsterdam: Elsevier.

Roediger, H. L. III, Weldon, M. S., \& Challis, B. H. (1989). Ex- 
plaining dissociations between implicit and explicit measures of retention: A processing account. In H. L. Roediger III \& F. I. M Craik (Eds.), Varieties of memory and consciousness: Essays in honour of Endel Tulving (pp. 3-41). Hillsdale, NJ: Erlbaum.

SCHACTER, D. L. (1987). Implicit memory: History and current status. Journal of Experimental Psychology: Learning, Memory, \& Cognition, 13, 501-518.

SCHACTER, D. L. (1994). Priming and multiple memory systems: Perceptual mechanisms of implicit memory. In D. L. Schacter \& E. Tulving (Eds.), Memory systems 1994 (pp. 233-268). Cambridge, MA: MIT Press.

Schacter, D. L., Alpert, N. M., Savage, C. R., Rauch, S. L., \& AlPert, M. S. (1996). Conscious recollection and the human hippocampal formation: Evidence from positron emission tomography. Proceedings of the National Academy of Sciences, 93, 321-325.

Schacter, D. L., CoOper, L. A., \& Delaney, S. M. (1990). Implicit memory for unfamiliar objects depends on access to structural descriptions. Journal of Experimental Psychology: General, 119, 5-24.

SEAmon, J. G., Brody, N., \& KaufF, D. M. (1983). Affective discrimination of stimuli that are not recognized: Effects of shadowing, masking, and cerebral laterality. Journal of Experimental Psychology: Learning, Memory, \& Cognition, 9, 544-555.

Seamon, J. G., Ganor-Stern, D., Crowley, M. J., Wilson, S. M., Weber, W. J., O'Rourke, C. M., \& Mahoney, J. K. (1997). A mere exposure effect for transformed three-dimensional objects: Effects of reflection, size, or color changes on affect and recognition. Memory \& Cognition, 25, 367-374.

SeAmon, J. G., McKenna, P. A., \& Binder, N. (1998). The mere exposure effect is differentially sensitive to different judgment tasks. Consciousness \& Cognition, 17, 85-105.

Seamon, J. G., Williams, P. C., Crowley, M. J., Kim, I. J., Langer, S. A., Orne, P. J., \& Wishengrad, D. L. (1995). The mere exposure effect is based on implicit memory: Effects of stimulus type, encoding conditions, and number of exposures on recognition and affect judgments. Journal of Experimental Psychology: Learning, Memory, \& Cognition, 21, 711-721.

Sluckin, W., Colman, A. M., \& Hargreaves, D. J. (1980). Liking words as a function of the experienced frequency of their occurrence. British Journal of Psychology, 71, 163-169.

SQUiRE, L. R. (1992). Memory and the hippocampus: A synthesis from findings with rats, monkeys, and humans. Psychological Review, $\mathbf{9 9}$, 195-231.

THORNDIKE, E. L., \& LORGE, I. (1944). The teacher's word book of 30,000 words. New York: Teachers College Press.

Tulving, E., \& Schacter, D. L. (1990). Priming and human memory systems. Science, 247, 301-306.

WhittleseA, B. W. A., \& Williams, L. D. (1998). Why do strangers feel familiar, but friends don't? The unexpected basis of feelings of familiarity. Acta Psychologica, 98, 141-166.

Whittlesea, B. W. A., \& WilliaMs, L. D. (2000). The source of feelings of familiarity: The discrepancy-attribution hypothesis. Journal of Experimental Psychology: Learning, Memory, \& Cognition, 26, $547-565$.

ZAJONC, R. B. (1968). Attitudinal effects of mere exposure. Journal of Personality \& Social Psychology Monographs, 9 (2, Pt. 2), 1-27.

ZaJonc, R. B. (1980). Feeling and thinking: Preferences need no inferences. American Psychologist, 35, 151-175.

ZAJONC, R. B. (2000). Feeling and thinking: Closing the debate over the independence of affect. In J. P. Forgas (Ed.), Feeling and thinking: The role of affect in social cognition (pp. 31-58). Cambridge: Cambridge University Press.

Zárate, M. A., Sanders, J. D., \& Garza, A. A. (2000). Neurological dissociations of social perception processes. Social Cognition, 18, 223-251. 
APPENDIX

List of Materials Used in Experiments 1 and 2

\begin{tabular}{|c|c|c|c|}
\hline A1 & A 2 & B1 & B2 \\
\hline \multicolumn{4}{|c|}{ Words } \\
\hline $\begin{array}{l}\text { couplet } \\
\text { outset } \\
\text { dryad } \\
\text { handbook } \\
\text { foothill } \\
\text { facet } \\
\text { fitful } \\
\text { ensconce } \\
\text { talcum } \\
\text { inverse } \\
\text { biting } \\
\text { uproot } \\
\text { adjudge } \\
\text { mutton } \\
\text { belie } \\
\text { hither }\end{array}$ & $\begin{array}{l}\text { convene } \\
\text { outlay } \\
\text { drier } \\
\text { harangue } \\
\text { foothold } \\
\text { fated } \\
\text { fiscal } \\
\text { encroach } \\
\text { tartan } \\
\text { inquest } \\
\text { binder } \\
\text { upkeep } \\
\text { adjunct } \\
\text { muzzle } \\
\text { beset } \\
\text { hinder }\end{array}$ & $\begin{array}{l}\text { crier } \\
\text { sodden } \\
\text { discord } \\
\text { barrow } \\
\text { farthest } \\
\text { foreclose } \\
\text { grisly } \\
\text { betide } \\
\text { castor } \\
\text { boredom } \\
\text { hedgerow } \\
\text { homestead } \\
\text { ingot } \\
\text { steely } \\
\text { bellows } \\
\text { rebate }\end{array}$ & $\begin{array}{l}\text { crony } \\
\text { socket } \\
\text { disdain } \\
\text { barter } \\
\text { fastness } \\
\text { footstool } \\
\text { gritty } \\
\text { bestir } \\
\text { casing } \\
\text { boulder } \\
\text { headland } \\
\text { housemaid } \\
\text { inset } \\
\text { stocky } \\
\text { beehive } \\
\text { refute }\end{array}$ \\
\hline \multicolumn{4}{|c|}{ Nonwords } \\
\hline $\begin{array}{l}\text { jarvoke } \\
\text { bolvene } \\
\text { medease } \\
\text { cidgree } \\
\text { perset } \\
\text { sparted } \\
\text { frantgin } \\
\text { malneath } \\
\text { magale } \\
\text { entort } \\
\text { locstall } \\
\text { venjust } \\
\text { sacrult } \\
\text { fulplore } \\
\text { forstound } \\
\text { barbness }\end{array}$ & $\begin{array}{l}\text { jarcree } \\
\text { bolmote } \\
\text { metcord } \\
\text { civfess } \\
\text { permay } \\
\text { spirmen } \\
\text { frolbuke } \\
\text { malcount } \\
\text { majane } \\
\text { enhaps } \\
\text { logceive } \\
\text { vextire } \\
\text { sarcbat } \\
\text { fulflict } \\
\text { forserve } \\
\text { battsome }\end{array}$ & $\begin{array}{l}\text { timvert } \\
\text { ebbtice } \\
\text { dipand } \\
\text { vigfeat } \\
\text { fundlige } \\
\text { orchtect } \\
\text { baggpall } \\
\text { perempt } \\
\text { plustween } \\
\text { aldain } \\
\text { hongage } \\
\text { captcile } \\
\text { tractopt } \\
\text { inpect } \\
\text { radbound } \\
\text { deesque }\end{array}$ & $\begin{array}{l}\text { tipvour } \\
\text { ebblect } \\
\text { dignon } \\
\text { volpeal } \\
\text { furnfuge } \\
\text { orimorse } \\
\text { balsolve } \\
\text { perlief } \\
\text { pluslogue } \\
\text { alsorb } \\
\text { hopceed } \\
\text { capflect } \\
\text { tradcoil } \\
\text { inhind } \\
\text { rascpend } \\
\text { decence }\end{array}$ \\
\hline
\end{tabular}

(Manuscript received June 3, 2003;

revision accepted for publication January 4, 2004.) 